\title{
Ureteral Access Sheath Influence on the Ureteral Wall Evaluated by Cyclooxygenase-2 and Tumor Necrosis Factor- $\alpha$ in a Porcine Model
}

\author{
Søren Kissow Lildal, MD, ,2 Rikke Nørregaard, PhD, Kim Hovgaard Andreassen, MD,,2 \\ Frederikke Eichner Christiansen, MD, ${ }^{1,2}$ Helene Jung, MD, PhD, ${ }^{1,2}$ \\ Malene Roland Pedersen,,4 and Palle Jörn Sloth Osther, MD, PhD ${ }^{1,2}$
}

\begin{abstract}
Objective: To examine the effect of ureteral access sheath (UAS) on the expression of the pro-inflammatory mediators cyclooxygenase-2 (COX-2) and tumor necrosis factor- $\alpha$ (TNF- $\alpha$ ) in the ureteral wall.

Material and Methods: In 22 pigs an UAS was inserted and removed after 2 minutes on one side and 2 hours on the contralateral side. Postoperatively ureters were excised in vivo, and tissue samples from the distal ( 2 minutes/ 2 hours) and proximal ureter ( 2 minutes/ 2 hours) were snap-frozen before quantitative polymerase chain reaction analysis of COX-2 and TNF- $\alpha$. Five unmanipulated ureteral units from other pigs served as the control group.

Results: Compared to controls COX-2 mRNA was significantly upregulated in all UAS treated ureteral groups. Similarly, TNF- $\alpha$ mRNA was upregulated in all groups except the 2-minute proximal ureteral group. Both COX-2 and TNF- $\alpha$ expression were significantly higher in the distal than in the proximal ureter in the UAS treated ureters. After UAS insertion for 2 minutes, expression levels in the distal ureter were increased 6.5- and 8 -fold for COX-2 and TNF- $\alpha$, respectively; and after 2 hours of UAS placement COX-2 and TNF- $\alpha$ mRNA expression levels were increased 9- and 9.5-fold, respectively.

Conclusion: The pro-inflammatory mediators COX-2 and TNF- $\alpha$ were significantly upregulated in the ureteral wall by the influence of UAS. These findings may have implications for postoperative pain, drainage, and complications.
\end{abstract}

Keywords: ureter, ureteral access sheath, cyclooxygenase-2, tumor necrosis factor- $\alpha$, ureteroscopy, complications

\section{Introduction}

$\mathbf{U}$ SING URETERAL ACCESS SHEATH (UAS) in retrograde intrarenal surgery (RIRS) has several advantages, such as reducing intrarenal pressure and easing multiple reentries. ${ }^{1-4}$ A downside of UAS usage is the risk of harming the ureteral wall, when inserting an instrument of larger diameter than the scope itself. ${ }^{3,5}$ Furthermore, by keeping the UAS in situ during the operation, ischemic and inflammatory changes may be induced, potentially leading to temporary or chronic changes in the function of the ureter. ${ }^{6,7}$ Such changes may not be recognized during the endoscopic procedure, but may be involved in the pathogenesis of postoperative pain, drainage problems, and complications. ${ }^{6}$

Pro-inflammatory mediators cyclooxygenase-2 (COX-2) and tumor necrosis factor- $\alpha$ (TNF- $\alpha)$ are increased in the ureteral wall by the influence of UAS. ${ }^{8-12}$ Elevated COX-2 expression is known to occur in urothelial cells during urinary tract obstruction, which increases COX-2-dependent prostanoid synthesis. ${ }^{9}$ Inhibition of cyclooxygenase (COX) activity

\footnotetext{
${ }^{1}$ Department of Urology, Urological Research Center, Lillebaelt Hospital, Vejle, Denmark.

${ }^{2}$ Institute of Regional Health Research, University of Southern Denmark, Vejle, Denmark.

${ }^{3}$ Institute of Clinical Research, Aarhus University, Aarhus, Denmark.

${ }^{4}$ Department of Radiology, Lillebaelt Hospital, Vejle, Denmark.
}

(c) Søren Kissow Lildal et al. 2017; Published by Mary Ann Liebert, Inc. This Open Access article is distributed under the terms of the Creative Commons Attribution Noncommercial License (http://creativecommons.org/licenses/by-nc/4.0/) which permits any noncommercial use, distribution, and reproduction in any medium, provided the original author(s) and the source are credited. 
with nonsteroidal anti-inflammatory drugs (NSAIDs) has proven to reduce pain in patients with ureteral colic or obstruction ${ }^{13}$ and intrarenal pressure and ureteral contractility in animal and in vitro experiments. ${ }^{9,14}$ TNF- $\alpha$ is a wellknown pro-inflammatory and cytotoxic cytokine that can induce apoptosis in many different cells in the organism and in the urinary system it is involved in pathologic renal conditions such as ischemia-reperfusion injury and obstructive uropathy, being synthesized in renal tubular epithelial cells and infiltrating macrophages. ${ }^{15,16}$ Based on these findings we hypothesized that ureteral wall distention due to UAS placement may lead to upregulation of COX-2 and TNF- $\alpha$, which subsequently could play an important role in postoperative symptoms and ureteral malfunction after UAS usage. We tested this hypothesis in a porcine model.

\section{Materials and Methods}

\section{Experimental animals and surgical procedure}

Before the study, a pilot study was performed, in which the most appropriate UAS size was selected. The ureter size of the type of pigs evaluated in the present study was found to be slightly larger than human ureters. The clinical feeling of placing a $13 / 15 \mathrm{~F}$ UAS in the pigs was equivalent to placing $12 / 14 \mathrm{~F}$ UASs in human ureters, and therefore, this UAS size was chosen for the experiment.

The animal protocols were approved by The National Animal Experiments Inspectorate (Copenhagen, Denmark). Studies were performed on 27 anesthetized female pigs (including five controls) weighing $55 \mathrm{~kg}$ (Påskehøjgård, Ølsted, Denmark). The pigs were fed a standard diet during breeding. Before the study they had access to water, but were fasting 12 hours before anesthesia.

After premedication with azaperone $(4 \mathrm{mg} / \mathrm{kg})$ and midazolam $(4 \mathrm{mg} / \mathrm{kg})$, anesthesia was induced by propofol (4$20 \mathrm{mg} / \mathrm{kg}$ ) and maintained with sevoflurane (1.2 MAC) and fentanil $(0.03 \mathrm{mg} / \mathrm{kg} / \mathrm{hours})$. The pigs were orotracheally intubated and mechanically ventilated (GE Healthcare S5 Avance). Hydration was maintained by administration of saline $(9 \mathrm{~g} / \mathrm{L}$ sodium chloride; $10 \mathrm{~mL} / \mathrm{kg} /$ hours $)$ at a temperature of $37^{\circ} \mathrm{C}$ through an ear vein.

A cystoscope was inserted through the urethra into the bladder. A ureteral catheter (Selectip ${ }^{\circledR}$; Bard Medical, Covington, GA) was placed in the distal part of the ureter, and a retrograde pyelography was performed to visualize the anatomy of the upper urinary tract. A guidewire (Sensor ${ }^{\circledR}$; Boston Scientific, Marlborough, MA) was placed through the ureteral catheter to the renal pelvis, and the cystoscope was removed.

Over the guidewire a hydrophilic UAS (Navigator ${ }^{\mathrm{TM}}$ Ureteral Access Sheath; Boston Scientific) 13/15F was inserted on one side and removed after 2 minutes. The insertion procedure was repeated on the contralateral side, where the UAS was left in position for 2 hours before extraction. UAS placement was controlled by fluoroscopy, ensuring that all UASs reached the proximal part of the ureter. UAS insertion was performed by two experienced endourologists (K.H.A., P.J.S.O.). During insertion of the UASs no excessive resistance was encountered. A safety wire was not placed outside the sheath. Although this is often clinical practice, this was avoided to secure uniform treatment of all ureters and to rule out the possibility that the safety wire would cause local damage leading to inflammation in the analyzed tissue.
Through a midline abdominal incision both ureters were exposed and carefully excised in vivo between the ureteropelvic junction and the ureterovesical junction. One centimeter of ureteral tissue was collected from the distal and proximal ureter, respectively. This specimen was prepared further below/above the resection line, in order not to examine tissue close to the surgical trauma and to ensure examining tissue affected by the UAS. The surrounding fat and serosa were meticulously removed within minutes before the material was snap-frozen in liquid nitrogen and stored at $-80^{\circ} \mathrm{C}$.

Finally, the pigs were euthanized under anesthesia with $20 \mathrm{~mL}$ of pentobarbital, $200 \mathrm{mg} / \mathrm{mL}$.

\section{Quantitative polymerase chain reaction}

Total RNA was isolated using TRIzol Reagent (Life Technologies, Thermo Fisher Scientific, Cambridge, MA) according to manufacturer's instructions. RNA was quantitated by spectrophotometry and stored at $-80^{\circ} \mathrm{C}$. cDNA was synthesized from $0.5 \mu \mathrm{g}$ RNA with the AffinityScript QPCR cDNA Synthesis Kit (Life Technologies, Thermo Fisher Scientific). For quantitative polymerase chain reaction (q-PCR), 100 ng cDNA served as a template for PCR amplification using Brilliant SYBR Green QPCR Master Mix according to the manufacturer's instruction (Life Technologies). mRNA levels were validated by an Aria Mx3000P q-PCR System (Agilent Technologies, Santa Clara, CA) with $\beta$-actin as a control gene. A standard curve was constructed by plotting threshold cycle (Ct values) against serial dilutions of cDNA. The following primer sequences were used: COX-2: sense 5'-CAA AAC CGT ATT GCT GCT GA- ${ }^{\prime}$ and antisense 5' $^{\prime}$ CAA AAC CGT ATT GCT GCT GA-3'; TNF- $\alpha$ : sense $5^{\prime}$-GGC TGC CTT GGT TCA GAT GT- $3^{\prime}$ and antisense $5^{\prime}$ CAG GTG GGA GCA ACC TAC AGT T- $3^{\prime}$; and $\beta$-actin: sense 5'-CAT CAC CAT TGG CAA TGA GCG-3' and antisense $5^{\prime}$-CTA GAA GCA TTT GCG GTG GAC- $3^{\prime}$. Samples were amplified in duplicate in 96-well plates, and PCR was performed for 40 cycles consisting of denaturation for 30 seconds at $95^{\circ} \mathrm{C}$ followed by annealing and polymerization at $60^{\circ} \mathrm{C}$ for 1 minute. Emitted fluorescence was detected during the annealing/extension step in each cycle.

\section{Statistics}

COX-2 and TNF- $\alpha$ mRNA results from the samples were normalized for $\beta$-actin. Values are presented as group mean \pm SEM and 95\% confidence intervals. Statistical comparisons between experimental groups were made by a standard twosample $t$-test following log transformation of data for normality. $p<0.05$ was considered significant.

\section{Results}

Bilateral proximal and distal ureteral tissue samples were collected from all 22 pigs treated with UAS, resulting in 22 distal and proximal 2-minute samples and 22 distal and proximal 2-hour samples. Five age- and weight-matched pigs served as controls.

During q-PCR analysis, two of the short-term UAS treatment specimens were excluded from the study because of an error in sampling and isolation of RNA. 
Table 1. Ureteral Cyclooxygenase-2 mRNA

EXPRESSION (ARBITRARY UNITS) IN CONTROLS and Ureteral Access Sheath Treated Animals

\begin{tabular}{|c|c|c|c|c|c|c|}
\hline COX-2 & $\begin{array}{c}\text { Control } \\
\text { prox }\end{array}$ & $\begin{array}{c}\text { Control } \\
\text { dist }\end{array}$ & $\begin{array}{c}2 \\
\text { minutes } \\
\text { prox }\end{array}$ & $\begin{array}{c}2 \\
\text { minutes } \\
\text { dist }\end{array}$ & $\begin{array}{c}2 \\
\text { hours } \\
\text { prox }\end{array}$ & $\begin{array}{c}2 \\
\text { hours } \\
\text { dist }\end{array}$ \\
\hline & 5 & 5 & 20 & 22 & 22 & 22 \\
\hline Mean & 0.11 & 0.13 & $0.35^{\mathrm{a}}$ & $0.83^{\mathrm{a}, \mathrm{b}}$ & $0.48^{\mathrm{a}}$ & $1.17^{\mathrm{a}, \mathrm{b}}$ \\
\hline SD & 005 & 007 & 0.29 & 0.57 & 0.49 & 1.10 \\
\hline SEM & 0.02 & 0.03 & 0.09 & 0.18 & 0.11 & 0.25 \\
\hline
\end{tabular}

Number of animals, Mean value, SD, and SEM for each study group divided into subgroups of distal and proximal ureteral samples. ${ }_{p} p<0.05(0.05-0.0001)$ compared with controls.

${ }^{\mathrm{b}} p<0.05(0.05-0.0001)$ distal part of the ureter compared with the proximal part within each group.

COX-2 = cyclooxygenase -2 .

\section{COX-2 expression in the ureteral wall was increased in response to the use of UAS}

COX-2 mRNA expression from control ureters yielded low levels, and there was no difference between the distal and the proximal ureter $(p=0.79)$ (Table 1; Figs. 1 and 2).

In the 2-hour UAS treatment group COX-2 mRNA expression was markedly increased in both the distal $(p<0.0001)$ and proximal ureter $(p<0.05)$, compared to controls (Fig. 2). Expression was raised 9-fold in the distal ureter and 4.5-fold in the proximal ureter (Fig. 1). In addition, expression was more than doubled in the distal compared to the proximal ureter $(p<0.001)$, (Figs. 1 and 2). After only 2 minutes followed by a period of 2 hours of rest and reperfusion, expression was increased 6.5 -fold distally $(p<0.0001)$ and 3 -fold proximally $(p<0.01)$, compared to controls (Figs. 1 and 2). In the 2minute group the expression was also significantly more elevated $(p<0.05)$ in the distal compared to the proximal ureter (Figs. 1 and 2).

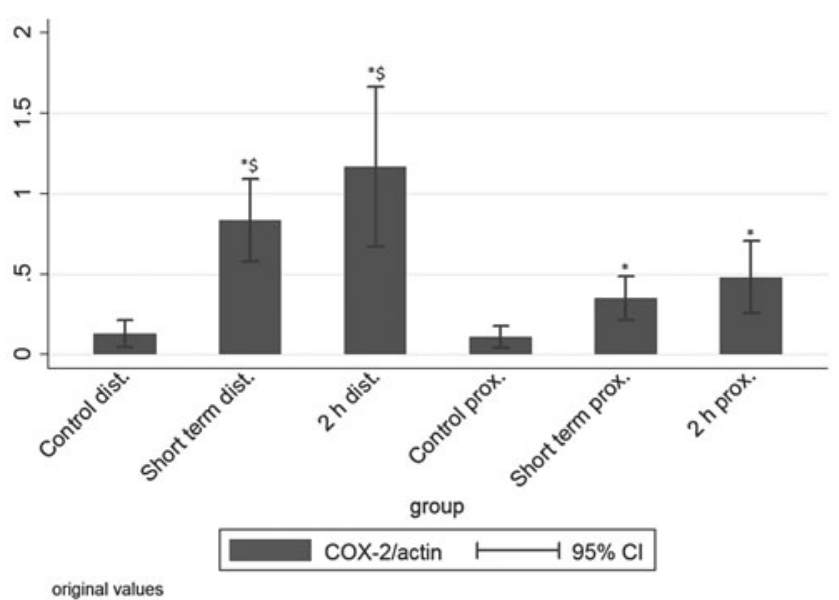

FIG. 1. Ureteral expression of COX-2 mRNA (arbitrary units). The depicted values are calculated group means according to Table $1 .{ }^{*} p<0.05(0.05-0.0001)$ compared with controls. ${ }^{\$} p<0.05(0.05-0.0001)$ distal part of the ureter compared with the proximal part within each group. Short term $=2$ minutes. COX-2 = cyclooxygenase -2 .

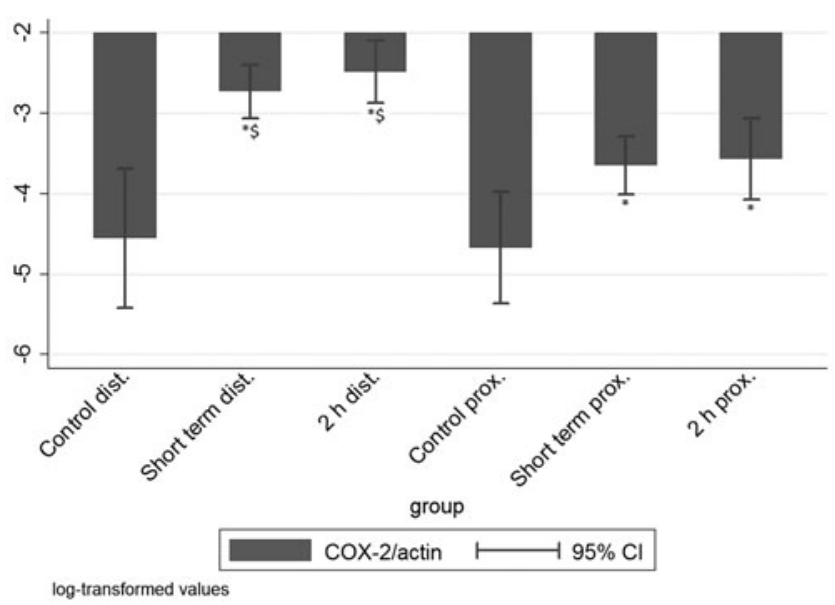

FIG. 2. Log-transformed values of the measured COX-2 mRNA expression normalized for $\beta$-actin $(95 \% \mathrm{CI})$. $* p<0.05(0.05-0.0001)$ compared with controls. ${ }^{\$} p<0.05$ (0.05-0.0001) distal part of the ureter compared with the proximal part within each group. Short term $=2$ minutes. $\mathrm{CI}=$ confidence interval.

\section{$T N F-\alpha$ expression in the ureteral wall was increased in response to the use of UAS}

TNF- $\alpha$ mRNA expression in controls was low, and there was no difference between distal and proximal ureter $(p=0.28)$ (Table 2; Figs. 3 and 4). In the treatment groups, we found highly elevated levels of expression in the ureteral wall (Table 2; Figs. 3 and 4). Following 2-hour UAS placement, TNF- $\alpha$ was increased 9.5 -fold in the distal ureter $(p<0.001)$ and 2-fold proximally $(p<0.05)$, compared to controls (Figs. 3 and 4). Similar to COX-2 expression, short-term treatment also resulted in marked and significant increase of TNF- $\alpha$ expression level in the distal ureter compared to controls $(p<0.001)$ (Figs. 3 and 4 ). The expression levels were not significantly increased in the proximal ureter. Both 2 hours and 2 minutes of UAS placement resulted in higher TNF- $\alpha$ levels in distal compared to proximal ureteral samples (Figs. 3 and 4). No significant differences were found between the 2-hour and 2-minute group.

Table 2. Ureteral Tumor Necrosis Factor- $\alpha$ mRNA EXPRESSION (ARBITRARY UNITS) IN CONTROLS and Ureteral Access Sheath Treated Animals

\begin{tabular}{lcccccc}
\hline TNF- $\alpha$ & $\begin{array}{c}\text { Control } \\
\text { prox }\end{array}$ & $\begin{array}{c}\text { Control } \\
\text { dist }\end{array}$ & $\begin{array}{c}2 \\
\text { minutes } \\
\text { prox }\end{array}$ & $\begin{array}{c}2 \\
\text { minutes } \\
\text { dist }\end{array}$ & $\begin{array}{c}2 \\
\text { hours } \\
\text { prox }\end{array}$ & $\begin{array}{c}2 \\
\text { hours } \\
\text { dist }\end{array}$ \\
\hline$N$ & 5 & 5 & 20 & 22 & 22 & 22 \\
Mean & 0.35 & 0.25 & 0.67 & $2.02^{\mathrm{a}, \mathrm{b}}$ & $0.72^{\mathrm{a}}$ & $2.48^{\mathrm{a}, \mathrm{b}}$ \\
SD & 0.16 & 0.12 & 0.52 & 2.60 & 0.50 & 4.00 \\
SEM & 0.07 & 0.05 & 0.16 & 0.82 & 0.11 & 0.89 \\
\hline
\end{tabular}

Number of animals, Mean value, SD, and SEM for each study group divided into subgroups of distal and proximal ureteral samples.

${ }_{\mathrm{b}}^{\mathrm{a}} p<0.05(0.05-0.001)$ compared with controls.

${ }^{\mathrm{b}} p<0.05(0.05-0.005)$ distal part of the ureter compared with the proximal part within each group.

$\mathrm{TNF}-\alpha=$ tumor necrosis factor $-\alpha$. 


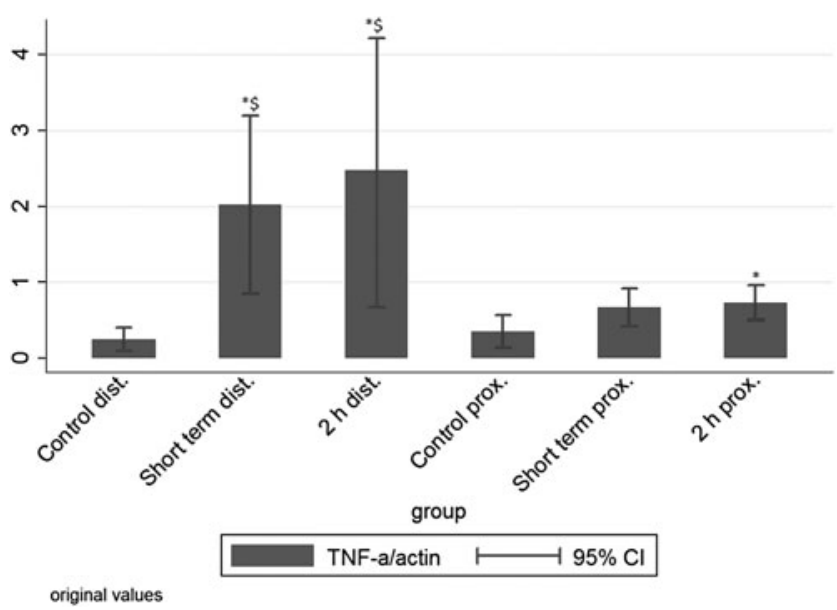

FIG. 3. Ureteral expression of TNF- $\alpha$ mRNA (arbitrary units). The depicted values are calculated group means according to Table $2 . * p<0.05(0.05-0.001)$ compared with controls. ${ }^{\$} p<0.05(0.05-0.005)$ distal part of the ureter compared with the proximal part within each group. Short term $=2$ minutes. TNF- $\alpha=$ tumor necrosis factor $-\alpha$.

\section{Discussion}

This porcine model intended to simulate the conditions that exist during RIRS in humans using an average size UAS and keeping this in situ in the ureter for 2 hours, which is approximately the maximum duration of this type of operation. Thereby, we aimed to create a plausible worst-case scenario for ureteral wall ischemia and stretch.

It is obvious that forced manipulation of a UAS in a narrow ureter may result in ureteral damage with subsequent risk of stricture development. In 359 patients, who underwent RIRS for kidney stones with usage of $12 / 14 \mathrm{~F}$ UAS, ureteral wall lesions could be endoscopically visualized in $46.5 \%, 13.4 \%$ representing high-grade, beyond the

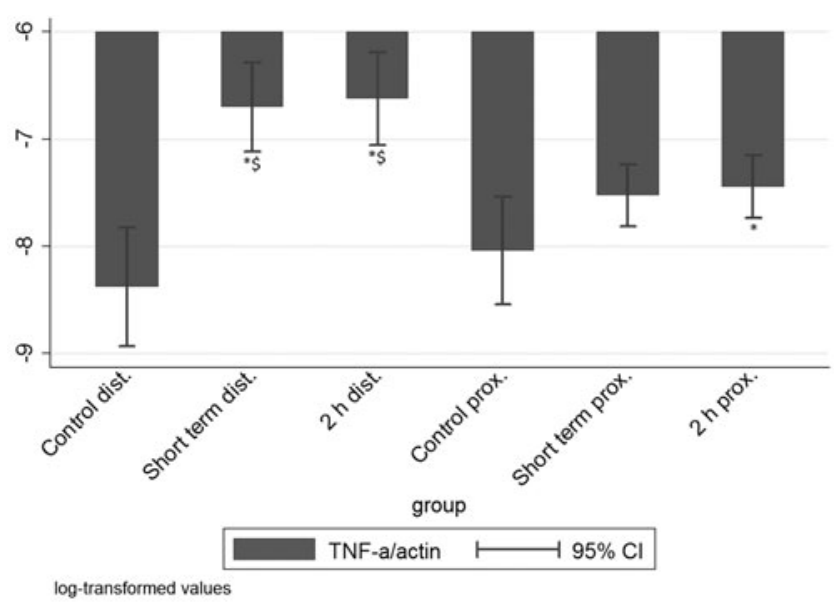

FIG. 4. Log-transformed values of the measured TNF- $\alpha$ mRNA expression normalized for $\beta$-actin $(95 \% \mathrm{CI}) .{ }^{\$} p<0.05$ $(0.05-0.005)$ distal part of the ureter compared with the proximal part within each group. ${ }^{*} p<0.05(0.05-0.001)$ compared with controls. Short term $=2$ minutes. mucosa, injuries. ${ }^{5}$ Even if ureteral lesions cannot be endoscopically visualized, UAS placement may cause reactions in the urothelium and smooth muscle layers, as reflected by postoperative pain and need for postoperative drainage (Double-J stenting). The present data suggest that pro-inflammatory mediators may be involved in such UAS related morbidity.

Only a few studies have been performed to assess the risk of UAS induced damage to the ureter, and most of the work addressed visible ureteral lesions rather than ischemic and inflammatory reactions. ${ }^{5,7,17}$ It has been shown that increased wall tension in both acute and chronically obstructed ureters in rabbits resulted in a significant decrease in smooth muscle blood perfusion evaluated by laser Doppler measurements. ${ }^{18}$ Another animal study on swine showed that placing a 12/14F UAS or larger for 70 minutes resulted in an initial decrease of intraoperative ureteral wall blood flow to below $50 \%$ of baseline. The ureters were excised and histologic examination found nuclear changes, inflammation, and ureteralwall thickening with collagen deposition, ${ }^{7}$ confirming our findings that significant changes occur following ureteral distention.

\section{COX-2 and TNF- $\alpha$ in the ureter}

It is known that obstruction leading to distention and stretch of the ureter causes severe pain and altered contractility. ${ }^{19-22}$ Prostanoids have been found to play a role in the stimulation of these reactions. ${ }^{23-25}$ The prostanoids are synthesized by conversion of arachidonic acid, and this reaction is catalyzed by $\mathrm{COX}$ as the rate-limiting enzyme. ${ }^{9}$ COX-2 is relatively unexpressed under normal conditions in most cells, whereas elevated levels are found during inflammation. ${ }^{26}$ Elevated COX-2 expression is known to occur in urothelial cells during urinary tract obstruction, which increases COX-2-dependent prostanoid synthesis. ${ }^{9}$ Inhibition of COX activity leads to reduction of prostanoid synthesis and correspondingly, NSAIDs may be used to reduce pain and contractility in patients with ureteral colic or obstruction. $^{13,27,28}$

Previous studies have shown that both COX-2 mRNA and protein levels are upregulated in chronically obstructed human ureters, ${ }^{8}$ and immunohistochemical analysis has detected COX-2 in both smooth muscle and urothelium. ${ }^{9}$ In a human study, chronically obstructed ureters were found to express four times more COX-2 mRNA than unobstructed controls. The same study showed a four-fold induction in COX-2 expression after 6 hours of acute ureteral obstruction in swine ureters harvested ex vivo. ${ }^{11}$ In a similar study using mice subjected to unilateral ureteral obstruction, COX-2 levels in whole ureteral tissue extracts were increased nine-fold after 6 hours compared to unobstructed controls. ${ }^{10}$

A study in rats subjected to 24 hours of ureteral obstruction showed an 18-fold increase in COX-2 mRNA in the proximal obstructed part, compared to the distal unobstructed part. Upon treatment with a selective COX-2 inhibitor, the postobstruction intraluminal pressure increase was significantly lower than in controls, indicating that increased COX-2 expression plays a part in elevated pressure in the upper urinary tract during obstruction. ${ }^{9}$ 
A few studies exist regarding the role and function of $\mathrm{TNF}-\alpha$ in the human ureter. In a study of 30 patients, serum TNF- $\alpha$ levels were significantly increased after 1 and 48 hours following ureteroscopic lithotripsy, ${ }^{29}$ and in another study it was found significantly more abundant in the ureter of children with vesicoureteral reflux than in healthy controls. $^{12}$

\section{COX-2 and TNF- $\alpha$ expression in the ureteral wall in response to the use of UAS}

The present study demonstrated that the use of UAS resulted in a significant upregulation of COX-2 and TNF- $\alpha$ mRNA expression. This was evident following just a few minutes of UAS placement. The elevated expression levels were comparable to what has previously been reported after several hours of ureteral obstruction. ${ }^{8,9,11}$ Furthermore, this effect persisted after 2 hours of rest and reperfusion before tissue sampling was performed. To our knowledge this is the first study showing such a substantial impact on COX-2 and TNF- $\alpha$ expression in the ureter by what may be characterized as a minimal surgical intervention.

After leaving the UAS in the ureter for 2 hours, we found an upregulation of both $\mathrm{COX}-2$ and $\mathrm{TNF}-\alpha$ as much as ninefold compared to controls. This increase is twice as high as what has previously been found in studies of COX-2 using chronically obstructed human ureters and experimental ureteral obstruction in pigs. ${ }^{8,11}$ Similar studies regarding TNF- $\alpha$ induction in the human ureter after instrumentation have not been published; however, our results are supported by the findings of Schwentner and colleagues, ${ }^{12}$ who showed that TNF- $\alpha$ levels were significantly higher in children with vesicoureteral reflux than in age-matched autopsy controls, and by Bantis and colleagues, ${ }^{29}$ who found doubling of serum values 1 hour after ureteroscopic lithotripsy.

As might be expected, the upregulation of pro-inflammatory mediators was stronger and more significant in the long-term UAS treatment group than in the short-term group (Tables 1 and 2; Figs. 1-4). It was noteworthy, however, that the expression in the short-term group was quite extensive, indicating that even short endourologic procedures may elicit a profound local inflammatory response, which in the ureter may lead to tissue edema and postoperative upper urinary tract obstruction. Comparing distal versus proximal ureteral tissue samples, we found that expression levels of proinflammatory mediators in the distal ureters were two to three times higher than in the proximal. This was observed in both groups. As the whole ureter is exposed to similar nervous and humoral stimuli, it can be reasoned that the direct physical stress applied to the distal ureter during insertion of the UAS is more pronounced compared to the proximal part. Thus, the distal ureter seems to be more vulnerable to UAS insertion than its proximal counterpart.

\section{Clinical implications}

In literature some studies exist on possible physiologic roles of COX-2 and TNF- $\alpha$ in the bladder and kidneys, but much less can be found on the effects of upregulation of these in the ureter. In bladder obstruction in mice, COX-2 activation occurs primarily in the smooth muscle cells in response to mechanical stretch, which suggests that stretch-activated COX-2 expression may play a role in bladder smooth muscle cell proliferation and pathologic bladder wall thickening after obstruction. ${ }^{30}$

Although no similar knowledge exists on the extended effects following ureteral wall stretch, it can be hypothesized that inflammatory responses in the ureter may also to some degree stimulate smooth muscle cell proliferation and connective tissue fibrosis, which are supported by the findings of Lallas and colleagues. ${ }^{7}$ Considering the fact that stone forming patients are likely to have multiple procedures performed, the risk of developing strictures or gradual loss of ureteral motor function may be considerable over time.

The effects of NSAID on pain and inflammation have long been utilized in the treatment of acute renal colic. ${ }^{13} \mathrm{~A}$ selective COX-2 inhibitor and a nonselective COX inhibitor reduced ureteral contractility in both porcine and human ureteral segments in vitro. ${ }^{14}$ Treatment with the COX-2 inhibitor, Celecoxib, completely abolished the expression of COX-2 and prostaglandin E2 (PGE2) in the smooth muscle layer of ligated ureters, and the severity of hydroureter and fibrosis of the muscle layer was significantly attenuated in a rat experiment. ${ }^{31}$ Another study on human ureter showed that the selective COX-2 inhibitor NS-398 reduced tonic and phasic contraction. ${ }^{32}$ In a swine study, diclofenac and NS398, effectively and reversibly, inhibited ureteral contractions. ${ }^{33}$ These studies show that reducing ureteral muscle tone and activity, as well as reducing tissue fibrosis, is possible by means of COX inhibition.

Our data suggest that inhibition of COX-2 and TNF- $\alpha$ in the ureter, during and after endourologic procedures, may be a rational treatment option, potentially preventing pain and postoperative urinary tract obstruction, which might be reflected in a reduced need for postoperative stenting. This needs to be further confirmed in clinical trials, however.

\section{Limitations}

The UAS size $(13 / 15 \mathrm{~F})$ used in the experiment may be considered too large for clinical usage in humans, and this may have resulted in an exaggerated COX- 2 and TNF- $\alpha$ response. The ureters in the pigs chosen for the study were slightly larger than human ureters, however, and the UAS size $13 / 15 \mathrm{~F}$ was chosen to reflect clinical usage of UAS 12/ $14 \mathrm{~F}$ in humans. Still, comparisons of pro-inflammatory mediator responses between smaller and larger sheaths would have added valuable information to the data. In the present series only the effect of UAS placement was evaluated. Merely introducing an ureteroscope into the ureter possibly also would have resulted in increased upregulation of proinflammatory mediators. However, it is conceivable to believe that the response to a UAS, which necessarily has to be larger than the ureteroscope itself, will be more pronounced. Since our study did not include an ureteroscope arm, differences in the ureteral response between ureteroscope alone and usage of UAS could not be clarified, and this issue needs further investigations. In contrast, manipulation with an ureteroscope inside a UAS during RIRS may result in further friction between the UAS and the ureteral wall, potentially resulting in an even more pronounced inflammatory response. In addition, the role of prestenting, which in a clinical setting often will be done when a larger sized UAS is to be used, cannot be concluded upon from the present data. 


\section{Conclusion}

The pro-inflammatory mediators COX-2 and TNF- $\alpha$ were significantly upregulated in the ureteral wall by the influence of UASs. These findings may have implications for postoperative pain, drainage, and complications. Thus, selective inhibition of COX-2 and TNF- $\alpha$ may be a way to reduce UAS induced morbidity. This needs to be confirmed in future experiments and clinical trials.

\section{Acknowledgments}

The authors thank Gitte Kall and Gitte Skou for expert technical assistance. The Research Council of Lillebaelt Hospital and the Japanese-Swedish Research Foundation provided support for this study.

\section{Author Disclosure Statement}

No competing financial interests exist.

\section{References}

1. Auge BK, Pietrow PK, Lallas CD, Raj GV, Santa-Cruz RW, Preminger GM. Ureteral access sheath provides protection against elevated renal pressures during routine flexible ureteroscopic stone manipulation. J Endourol 2004; 18:33-36.

2. Kourambas J, Byrne RR, Preminger GM. Does a ureteral access sheath facilitate ureteroscopy? J Urol 2001;165:789793.

3. Kaplan AG, Lipkin ME, Scales CDJ, Preminger GM. Use of ureteral access sheaths in ureteroscopy. Nat Rev Urol 2016;13:135-140.

4. Monga M, Bhayani S, Landman J, Conradie M, Sundaram $\mathrm{CP}$, Clayman RV. Ureteral access for upper urinary tract disease: The access sheath. J Endourol 2001;15:831-834.

5. Traxer O, Thomas A. Prospective evaluation and classification of ureteral wall injuries resulting from the insertion of a ureteral access sheath during retrograde intra-renal surgery (RIRS). J Urol 2012;189:580-584.

6. Osther PJS, Pedersen KV, Lildal SK, Pless MS, Andreassen $\mathrm{KH}$, Osther SS, et al. Pathophysiological aspects of ureterorenoscopic management of upper urinary tract calculi. Curr Opin Urol 2015;26:63-69.

7. Lallas CD, Auge BK, Raj GV, Santa-Cruz R, Madden JF, Preminger GM. Laser Doppler flowmetric determination of ureteral blood flow after ureteral access sheath placement. J Endourol 2002;16:583-590.

8. Nakada SY, Jerde TJ, Jacobson LM, Saban R, Bjorling DE, Hullett DA. Cyclooxygenase-2 expression is upregulated in obstructed human ureter. J Urol 2002;168: 1226-1229.

9. Nørregaard R, Jensen BL, Topcu SO, Nielsen SS, Walter S, Djurhuus JC, et al. Cyclooxygenase type 2 is increased in obstructed rat and human ureter and contributes to pelvic pressure increase after obstruction. Kidney Int 2006;70: 872-881.

10. Sterrett SP, Wilkinson ER, Jerde TJ, Mellon WS, Nakada SY. Evaluation of urothelial stretch-induced cyclooxygenase-2 expression in a mouse ureteral obstruction model. J Endourol 2009;23:541-544.

11. Jerde TJ, Mellon WS, Bjorling DE, Nakada SY. Evaluation of urothelial stretch-induced cyclooxygenase-2 expres- sion in novel human cell culture and porcine in vivo ureteral obstruction models. J Pharmacol Exp Ther 2006; 317:965-972.

12. Schwentner C, Oswald J, Lunacek A, Pelzer AE, Fritsch H, Schlenck B, et al. Extracellular microenvironment and cytokine profile of the ureterovesical junction in children with vesicoureteral reflux. J Urol 2008;180:694-700.

13. Afshar K, Jafari S, Aj M, Eftekhari A, Ae M. Nonsteroidal anti-inflammatory drugs (NSAIDs) and non-opioids for acute renal colic (Review). Cochrane Database Syst Rev 2015:CD006027.

14. Nakada SY, Jerde TJ, Bjorling DE, Saban R. Selective cyclooxygenase-2 inhibitors reduce ureteral contraction in vitro: A better alternative for renal colic? J Urol 2000; 163:607-612.

15. Misseri R, Meldrum KK. Mediators of fibrosis and apoptosis in obstructive uropathies. Curr Urol Rep 2005;6: 140-145.

16. Meldrum KK, Meldrum DR, Meng X, Ao L, Harken AH. TNF-alpha-dependent bilateral renal injury is induced by unilateral renal ischemia-reperfusion. Am J Physiol Heart Circ Physiol 2002;282:540-546.

17. Traxer O, Wendt-Nordahl G, Sodha H, Rassweiler J, Meretyk S, Tefekli A, et al. Differences in renal stone treatment and outcomes for patients treated either with or without the support of a ureteral access sheath: The Clinical Research Office of the Endourological Society Ureteroscopy Global Study. World J Urol 2015;33:21372144.

18. Dinlenc CZ, Liatsikos EN, Smith AD. Ureteral ischemia model: An explanation of ureteral dysfunction after chronic obstruction. J Endourol 2002;16:47-50.

19. Djurhuus JC. Aspects of Renal Pelvic Function. Thesis, Copenhagen: University of Copenhagen, 1980.

20. Hammad FT, Lammers WJ, Stephen B, Lubbad L. Propagation of the electrical impulse in reversible unilateral ureteral obstruction as determined at high electrophysiological resolution. J Urol 2011;185:744-750.

21. Rose JG, Gillenwater JY. Effects of obstruction on ureteral function. Urology 1978;12:139-145.

22. Meldrum KK. Pathophysiology of Urinary Tract Obstruction, 11th ed. Campbell-Walsh Urology. Elsevier Inc., pp. 1089-1103.

23. Andersson KE, Forman A. Effects of prostaglandins on the smooth muscle of the urinary tract. Acta Pharmacol Toxicol (Copenh) 1978;43:90-95.

24. Lowry PS, Jerde TJ, Bjorling DE, Maskel JL, Nakada SY. Obstruction alters the effect of prostaglandin E2 on ureteral contractility. J Endourol 2005;19:183-187.

25. Cole RS, Fry CH, Shuttleworth KE. The action of the prostaglandins on isolated human ureteric smooth muscle. Br J Urol 1988;61:19-26.

26. Parente L, Perretti M. Advances in the pathophysiology of constitutive and inducible cyclooxygenases: Two enzymes in the spotlight. Biochem Pharmacol 2003;65:153159.

27. Chaignat V, Danuser H, Stoffel MH, Z'brun S, Studer UE, Mevissen M. Effects of a non-selective COX inhibitor and selective COX-2 inhibitors on contractility of human and porcine ureters in vitro and in vivo. Br J Pharmacol 2008; 154:1297-1307.

28. Jerde TJ, Calamon-Dixon JL, Bjorling DE, Nakada SY. Celecoxib inhibits ureteral contractility and prostanoid release. Urology 2005;65:185-190. 
29. Bantis A, Tsakaldimis G, Zissimopoulos A, Giannakopoulos S, Kalaitzis C, Pitiakoudis M, et al. Can tumor necrosis factor- $\alpha$ and interleukin- 6 be used as prognostic markers of infection following ureteroscopic lithotripsy? ISRN Urol 2014;2014:1-5.

30. Park JM, Yang T, Arend LJ, Schnermann JB, Peters CA, Freeman MR, et al. Obstruction stimulates COX-2 expression in bladder smooth muscle cells via increased mechanical stretch. Am J Physiol 1999;276:129-136.

31. Chuang Y-H, Chuang W-L, Huang S-P, Huang C-H. Cyclooxygenase-2 inhibitor ameliorates ureteric damage in rats with obstructed uropathy. Eur J Pharmacol 2007;569: 126-137.

32. Lee SY, Lee MY, Park SH, Kim TH, Moon YT, Han JH, et al. NS-398 (a selective cyclooxygenase-2 inhibitor) decreases agonist-induced contraction of the human ureter via calcium channel inhibition. J Endourol 2010;24: 1863-1868.

33. Mastrangelo D, Wisard M, Rohner S, Leisinger H, Iselin CE. Diclofenac and NS-398, a selective cyclooxygenase-2 inhibitor, decrease agonist-induced contractions of the pig isolated ureter. Urol Res 2000;28:376-382.
Address correspondence to: Palle Jörn Sloth Osther, MD, PhD Department of Urology Urological Research Center Lillebaelt Hospital

Kabbeltoft 25

Vejle 7100

Denmark

E-mail: palle.joern.osther@rsyd.dk

$\begin{aligned} & \text { Abbreviations Used } \\ \mathrm{COX}-2 & =\text { cyclooxygenase }-2 \\ \mathrm{NSAIDs} & =\text { nonsteroidal anti-inflammatory drugs } \\ \mathrm{PCR} & =\text { polymerase chain reaction } \\ \mathrm{PGE} 2 & =\text { prostaglandin } \mathrm{E} 2 \\ \mathrm{q}-\mathrm{PCR} & =\text { quantitative polymerase chain reaction } \\ \mathrm{RIRS} & =\text { retrograde intrarenal surgery } \\ \mathrm{TNF}-\alpha & =\text { tumor necrosis factor } \alpha \\ \mathrm{UAS} & =\text { ureteral access sheath }\end{aligned}$

